\title{
The Prototype Version for e-Material Creating and Formatting Application
}

\author{
Kristine MACKARE, Anita JANSONE, Ilja KONAREVS \\ Liepaja University, Liepaja, Liela Street 14, Latvia \\ kristine.mackare@liepu.lv, anita.jansone@liepu.lv
}

\begin{abstract}
It is believed, well-formatted e-materials could improve users reading comfort and vision health after screen-work. That can be followed by educational and life quality increase. There is a need for user-centric and adaptive educational e-materials. Users intuitive ask for the more individual approach for screen work what are related to people complain and objective findings. One of the possible solutions to reach improvement is the e-material formatting application. That can improve the comfort of using e-material in learning and study process and decrease near workload after screen work. Formatting to e-materials should be applied for natural and comfortable perception and in cooperation with visual processes. Also, they should be helping the learning process and facilitating memorization. Moreover, the goal of user-centric design could be reached by adapting text formatting for individual needs in addition. Already developed first version prototype gives the overview of application work to follow implemented working schemes, relationships between leading edges and collaboration process between edges and the user, material and database. For the possibility to give formatting recommendations, application collect necessary data from the user. That is followed by solution finding with a step-by-step recommendation and so-called tree-scheme of users answers and related application respond what gives a recommendation of text formatting and provides it. An application can be described from four sides: developers, e-material formatting users as readers, e-material creators and researchers.
\end{abstract}

Keywords. Application, e-learning, e-material, formatting, prototype.

\section{Introduction}

Reading from screens is a huge part of daily screen-work nowadays what is related to professionals in a wide range of occupations and all levels of education gainers as well as a big part of worldwide populations leisure time-spending form as screens surround us. (Simon, 2019; Mackare and Jansone, 2018a) Unfortunately, a significant part of users is not satisfied with screen reading comfort, especially in a continuous work period. The proportion of users frequently have essential complains and different ocular symptoms after near work what not rarely lead to the significant decrease of vision functions and changes in ocular health such as computer vision syndrome, digital eye fatigue or developing of high myopia. (Mackare and Jansone, 2018a; CooperVision, 2018; Blehm et al., 2005; Yan et al., 2008) In the long term, it brings up personal and professional life quality changes. 
Part of the responsibility lies in technology progress what is unstoppable due to the recently expanded digitalization of the world. Despite technology improvement and visual perception system adaptation, the evolution of visual perception and analysation system to different reading and perception model is not fast enough. There are specific in the humans' physiology of visual perception, analysation and comprehension system what gives humans the ability to distinguish between reality and on-screen visualisation. Same and related processes make a difference between reading printed material and screen reading. (Andreu-Sánchez et al., 2017; Carroll and Seeley, 2013; Zacks et al., 2009; Nielsen, 2000; Buckner et al., 2012)

Studies show as incoming information influences reading than both content and appearance of text are important. (Blehm et al., 2005) So, text formatting is fundamental as text appearance is an essential part not only of reading influence but also in textual material perception. More accessible precepted text is easier to analyse and comprehends. Formatting parameters as text font type, font size, space between lines, text line length and colours of letters and background plays an important role in that and must be appropriate for the user while screen reading. (Rayner, 1998; Dyson, 2004; Hall and Hanna, 2004) That is why it is believed, well-formatted e-materials could improve users reading comfort and vision health after screen-work.

That can be followed by educational and life quality increase as a positive effect on reducing eye fatigue. There is a need for user-centric and adaptive educational ematerials. Previous research show unambiguity in suggested formatting parameters for ematerials. (Mackare and Jansone, 2017a) Besides, users intuitive ask for the more individual approach for screen work what are related to people complain and objective findings. (Mackare and Jansone, 2018a)

One of the possible solutions to reach improvement in e-material formatting and users' comfort is the e-material formatting application. That can improve the comfort of using e-material in learning and study process and decrease near workload after screen work. Formatting to e-materials should be applied for natural and comfortable perception and in cooperation with visual processes. In addition, they should be helping the learning process and facilitating memorisation. Also, the goal of user-centric design could be reached by adapting text formatting for individual needs in addition as there are not the only group related parameters but several individual qualities what make differences in perception and comfort outcome.

\section{Previous work as the base for prototype}

\subsection{Current situation overview and grounds for app necessity}

Broad range literature research about currently offered and available recommendations, guidelines and methodologies for e-materials have been done. Suggested parameter analyses showed unambiguity in suggestions. Wide range of printed material recommendations is the primary choice for e-material formatting. An extended presentation about all collected data can be found in the previous publication. (Mackare and Jansone, 2017a) Related programs, applications and tools analyses show the same findings. (Ziverte, 2018)

Statistical data analyses both worldwide and local related to internet and digital device users as well as CBS statistical data analysis of population involved in different educational activities have been made. Users' complains, and vision problems related to 
near- and screen-work have been overviewed. (Mackare and Jansone, 2018a; Mackare and Jansone, 2018b) Found out that more than 90\% of respondents use devices to get information. Screen-user amount and using frequency and time collate with the increase of users complains increase and vision problem development. It can have a negative impact on users' vision as the eyes get tired of frequent reading, as shown in most often ocular symptoms and complains after screen work. (Mackare and Jansone, 2018c)

\subsection{Recommendations for e-material formatting}

E-material formatting recommendations in the application are based on developed recommendations for user-centric and adaptive educational e-material creation and formatting. Recommendations are based on user need and preferences research (Mackare and Jansone, 2018b; Mackare and Jansone, 2017b; Mackare and Jansone, 2018d), user habits research (Mackare and Jansone, 2018b), vision conditions, symptoms and refraction changes research from practice as patient data research and analyses. (Mackare and Jansone, 2018a; Mackare and Jansone, 2018b)

In our previous work (Mackare and Jansone, 2017a; Mackare and Jansone, 2018d) it was proposed that recommendations of four main parameters as font type, font size, line spacing and colour of text and background are suggested for e-material formatting. More parameters can be added in case if it can give improvements.

On the beginning research stages, targeting groups was primarily divided into three groups: children (7-15,) adults (16-39), and pre-seniors/seniors (40+) what roughly are applicable as related to vision development and vision function quality. (Ziverte, 2018; Mackare and Jansone, 2017b; Mackare and Jansone, 2018d)

After more detailed research and data analysis smaller age range was chosen for target groups: Children as pre-school 3-5 and grade-schooler 6-11, Teens 12-15, Youth16-25, Young adults 26-35, adults 36-39, middle-aged adults 40-55, senior adults 55+, elderly 65+. (Mackare and Jansone, 2019b) This division helps to create more personalised e-material formatting recommendations in the primary formatting steps.

\subsection{Concept}

The concept for application prototype has been developed. The main idea of the concept is shortly represented as three main edges of the app: user, interface and database, and collaboration processes between edges and the main idea of the app - text formatting of documents based on user groups. The concept must give a clear description of the application. It is important to give understanding for a programmer what exactly must be done to achieve the goal of the app. Fig. 1 represents an extended sequence diagram for application concept with main application working areas: data collecting, analyses and solution making, learning process, as well as a short inside view of processes in database. More detailed concept description is published previously. (Zigunovs et al., 2018; Mackare et al., 2018; Mackare and Jansone, 2019a) 


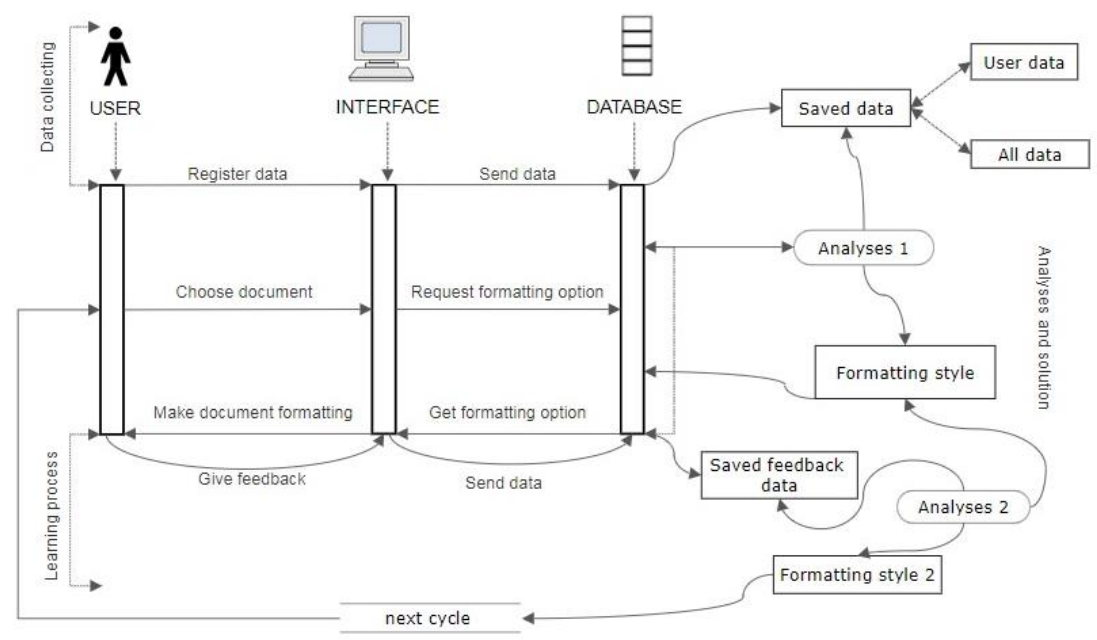

Fig.1. Extended sequence diagram for application concept

\subsection{App possible usage and integration in the e-study field}

The main reason for the development of the app is to improve e-material readability and perception. As e-materials is a huge part of e-studies, then possible app usage in the estudy field as an additional helping tool on Moodle type platforms to increase the satisfaction of the e-material usage during educational process is an important part of

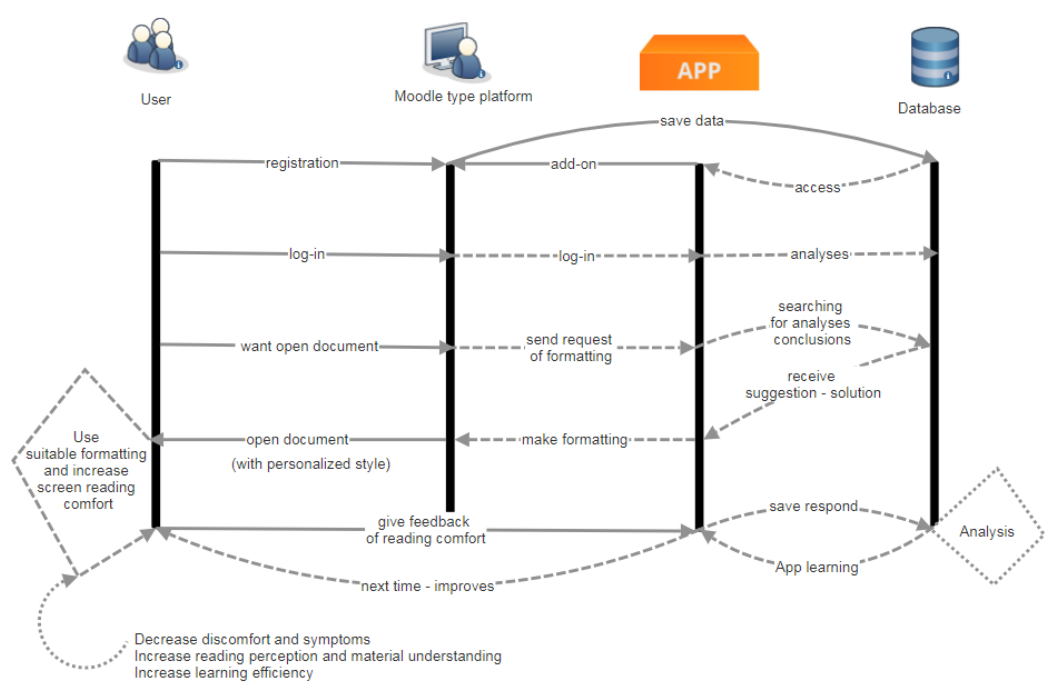

Fig. 2. Scheme of collaboration between User - Moodle type platform - App - database. 
development. Collaboration between User - Moodle type platform - App - the database is represented in fig.2. On Moodle type platform app works as an add-on. It makes it easier for the user to open just one webpage, log-in and fill in information sheets once. Also, the user always can disable app option if find its abilities inappropriate or unnecessary.

\section{The first version of the prototype}

\subsection{Technical solution}

Programming language at this phase of the prototype is not so important. Because the main goal of the first version of the app prototype was to understand is the possibility to realise the idea and how to carry out formatting functionality without user involvement the app makes all formatting process automatically.

Initially, there was an idea to use an XML programming language for the first application prototype development. Since XML was created in 1996, it is still actively used for visualization of documents and tables, data transfer and storage. As well as all MS office formats are based on XML.

However, to be confident of this choice has been analysed several of possible technical solutions as Visual Basic, Macros, OLE and XML programming languages. After analysis, the XML approach has been chosen as the best MS office file formatting methodology from the four approaches listed above. The XML approach has much more opportunity for future modifications and researches. This method is recognized as more advantage methods than other analysed solutions. (Mackare et al., 2018) Concluded part of the evaluation presented in table 1 .

Table 1. MS Word document formatting approach and evaluation criteria values

\begin{tabular}{|l|c|c|c|c|}
\hline & $\begin{array}{c}\text { Visual } \\
\text { Basic }\end{array}$ & Macros & XML & OLE \\
\hline OS independent & 3 & 1 & 3 & 1 \\
\hline Programming language & 2 & 2 & 2 & 1 \\
\hline Execution time & 1 & 1 & 3 & 1 \\
\hline $\begin{array}{l}\text { Opportunity to implement } \\
\text { additional functionality } \\
\text { except formatting }\end{array}$ & 1 & 0 & 3 & 1 \\
\hline \multicolumn{1}{|c|}{ Total: } & 7 & 4 & 11 & 4 \\
\hline
\end{tabular}

For the first version of the prototype focus of formatting was oriented only on MS office world document format.

\subsection{Prototype}

The prototype was developed as an Internet module, where when downloading of the document, the original document was obtained, which was modified using PHP on the server-side, and then the modified document was sent to client-side.

Currently, the app is made as separate app out of Moodle base, and frontpage of the app looks very simple. It has Log-in option for registered users with full accesses, and 
more deeply personalised formatting possibilities and two editing options - Edit full text and Edit styles, what are possible use without registration more like regular formatting programmes for text creating and formatting.

Users and application activity at the first step represent from the beginning when the user starts the activity by opening browser and web modules and reach authorization point. App asks is the user authorized or not and activity is to split into three types of users: two authorized users type as admin and authorized user, and other - nonauthorized user.

The part of the prototype works like this:

- the user is authorized with given necessary personal or individual information (or if he is not authorized, selects age category and additional information);

- $\quad$ next, the user clicks on the edit style button or text in the document;

- the user loads the document, app suggest appropriate formatting related to information about user or user selects all the necessary settings by discretion;

- the received document is automatically converted into an archive, shrinks, and the PHP already changes the structure of two defined files documents.xml and styles.xml.

- the user receives a modified document that is set up with related formatting style variation.

The second part of activity represents activity from dividing to users type and all possible activity for each type of user. Such activities as manage age category, manage fonts, manage font size, manage colours, save information, use app-generated personalized formatting (level 2), use app-generated formatting (level 1), made small changes of parameters in styles (listed from left to right). Also, there is an admin panel where the administrator has sub-groups of activities: add, edit or delete age categories, styles, fonts, font size or colours. All user actions bring to the result step where user get the formatted document.

The last step of current activity represents activity from result step or receiving formatted document until the complete end of the action. Authorized users should take further action as a log-out process before closing the browser.

\subsection{Prototype database tables with relationships}

An essential part of the application is database tables with relationships what is visually represented in fig.3. All users and administrators are listed in the user table; each user has a login, password, its age category and level of vision or existence of complains. There is a table of the age category, in which the category name and age period are indicated, for example, group 4 - users from 16 to 25 y.o. Another table is about the level of vision, in which it is indicated how bad or good the vision is for the person. The same table represents the existence or absence of complains and level of discomfort.

Further, there are two tables related to the style: colour and font. In the font table, only its full name is indicated, and in the colour table, there is the name of the colour and directly the hex code of this colour.

The last table or style sheet is one which lists the full and short style names, as well as other values, such as text size, fonts, colours, and other necessary parameters. 
There is a connection between the tables, namely, in the table of the users, there is an identifier of the age category and the level of view, which sends to the corresponding tables where the data comes from. In the style sheet, there are the same identifiers as in the user table, only in addition, there are identifiers of the text colour, background colour and font. The colour of the text and its background colour are sent to one table, where the data on the corresponding colour identifier is taken, also works with the font.

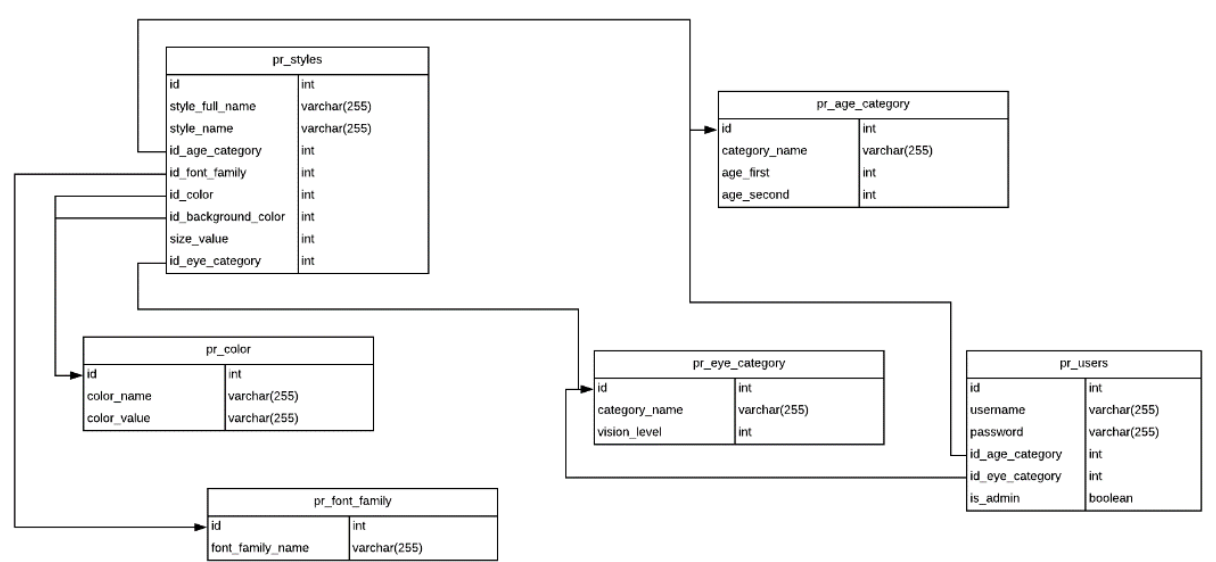

Fig.3. Database tables with relationships

\subsection{Application decision-making scheme}

For the most successful and more accurate formatting suggestion providing app must learn from active cases and users' feedback but to gain experience app must work from the beginning. To realize app working base knowledge have been given by previously developed formatting recommendations. The scheme as modified tree-scheme has been developed and given to app for decision making.

The first level, what is simplest, personalized formatting without detailed and more personalized suggestions are based on three users' question-answer analyses: age, gender and existence of complains. Application analyses data based on existing decision-tree scheme and generate propriety formatting style. First level e-material formatting personalization process is shown in fig. 4 .

The second level personalized formatting requests more complex analysis and are based on extended users' information. On the other hand, it gives more user-centric formatting possibilities and can provide higher comfort for the user and better screen work improvement. 


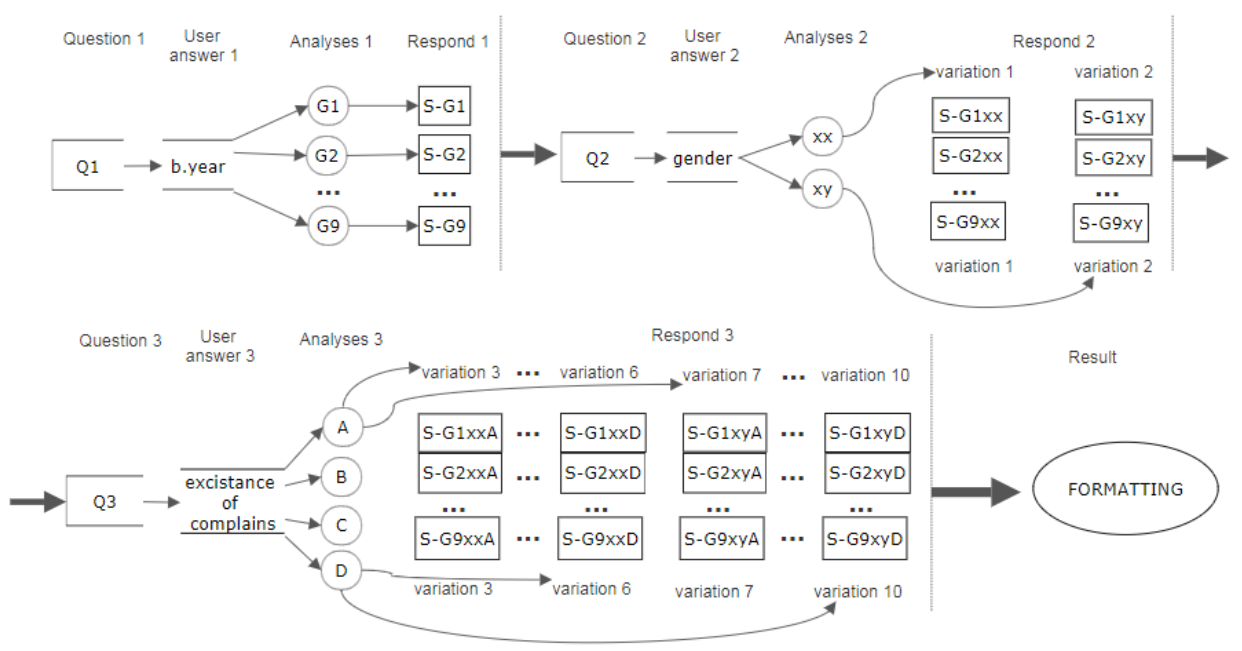

Fig. 4. Scheme of user responds and application decision making for appropriate style followed by formatting variation. The first level of personalized formatting without detailed and more personalized suggestions.

$\mathrm{Q}$ - question, $\mathrm{G}$ - age group, $\mathrm{S}$ - style, $\mathrm{xx}$ - women, $\mathrm{xy}$ - men,

A, B, C, D - specific respond about complains existence.

\section{Conclusions and future work}

Already developed first version prototype gives the overview of application work to follow implemented working schemes, relationships between main edges and the collaboration process with the user, material and database. For the possibility to give formatting recommendations, application collect necessary data from the user. That is followed by solution finding with a step-by-step recommendation and so-called treescheme of users answers and related application respond what gives a recommendation of text formatting and provides it. After the user has tried new formatting of e-material, the application provides a short questionnaire of user feedbacks. An application can be described from four sides: developers, e-material formatting users as readers, e-material creators and researchers.

Application prototype is developed on Moodle type platform base but with possible transformation and adaptation for a different environment and wider range of use. As the application is developed to give access to the database to researchers, it helps in userhabit research and allows to keep the application up to date to reach application learning process. That is an important part of nowadays user-centric designs for users' satisfaction.

After the development of the first version of the prototype, authors have concluded that it is not only possible to make such an application but that there is room for improvements. As the app will be developed to use on the e-study environment, it is thought to use PHP7 programming language, as it is the server language which is used for interaction between the browser and the server, which is a perfect option for this app development. Using PHP7 functions will allow overwrite the XML code, thus modifying 
the e-materials, updating them to learner needs. Secondary in the improved version of the prototype or final version of the app focus would be on all most popular formats of ematerials, including PDF. In theory, it is possible to develop the app as a web browser add-on which can modify any base code of the loaded webpage. Then it will be able to edit HTML format by modifying its CSS parameters. The third significant upgrade will be that the app will be made in such a way so it could be used with any e-material system not only Moodle. Moreover, as e-learning is getting more and more popular in web beyond traditional schools and universities, then authors concluded that the app must be able to format web materials that are viewable only in browser therefor edit HTML and CSS.

The system evaluation with users is a necessary future step. Currently, authors will be work on the improved version of the application and after the development of it are planned to make the Alpha test of the app with user-based testing.

\section{References}

Andreu-Sánchez, C., Martín-Pascual, M.Á., Gruart, A., Delgado-García, J.M. (2017). Looking at reality versus watching screens: Media professionalization effects on the spontaneous eyeblink rate, PLoS One. 2017; 12(5): e0176030

Blehm, C., Vishnu, S., Khattak, A., Mitra, S., Yee, R.W. (2005). Computer vision syndrome: a review, Surv. Ophthalmol. 2005 May-Jun;50(3):253-62.

Buckner, R.L., Snyder, A.Z., Sanders, A.L., Raichle, M.E., Morris, J.C. (2012). Functional brain imaging of young, nondemented, and demented older adults, J. Cogn. Neurosci. 12 (Suppl. 2), 24-34

Carroll, N., Seeley, W.P. (2013). Cognitivism, Psychology, and Neuroscience: Movies as Attentional Engines In: Shimamura AP, (Ed.) Psychocinematics Exploring cognition at the Movies. New York: Oxford University Press

CooperVision (2018). Digital Device Usage and Your Eyes Report, available at https://coopervision.com/sites/coopervision.com/files/coopervision-digital-device-usageand-your-eyes-report.pdf

Dyson, C.M. (2004). How physical text layout affects reading from screen, Behavior \& Information technology, November-December 2004, Vol.23 No6, 377-393

Hall, R.H., Hanna, P. (2004). The impact of web page text-background colour combinations on readability, retention, aesthetics and behavioural intention, Behaviour \& Information technology, May-June 2004, Vol.23, No3, 183-195

Mackare, K., Jansone, A. (2017a). Research of guidelines for designing e-study materials, Proceedings of ETR17. The 11th International Scientific and Practical Conference Environment. Technology. Resources. (15-17 Jun. 2017, Latvia) Volume 2 Index in SCOPUS

Mackare, K., Jansone, A. (2017b). Users' preferences of e-material formatting parameters, Proceedings of MAC-ETL17. Multidisciplinary Academic Conference on Education, Teaching and Learning (Dec. 2017, Czech Republic)

Mackare K., Jansone, A. (2018a). Digital Devices Use for Educational Reasons and Related Vision Problems, Proceedings of ICLEL18, The 4th International Conference on Lifelong Education and Leadership (2-4 Jul. 2018, Poland)

Mackare, K., Jansone, A. (2018b). Habits of Using internet and digital devices in education, Proceedings of SIE18. The International Scientific Conference Society. Integration. Education. (25-26 May 2018, Latvia) Volume V 
Mackare, K., Zigunovs, M., Jansone, A. (2018c). Justification of the need for a custom e-material creation program. Proceedings of the conference Society and Culture (may 2018, Liepaja, Latvia) (Original: Pielāgoto e-materiālu veidošanas programmas nepieciešamības pamatojums, Rakstu krājums konferences Sabiedrība un kultūra (maijs 2018, Liepāja, Latvija))

Mackare, K., Jansone, A. (2018d). Recommended formatting parameters for e-study materials, IJLEL JOURNAL Vol. 4 No 1

Mackare, K., Jansone, A., Zigunovs, M. (2018). E-material Creating and Formatting Application, Advances in Intelligent Systems and Computing 876, pp. 135-140

Mackare, K., Jansone, A. (2019a). The concept for e-material creating and formatting application prototype, Periodicals of Engineering and Natural Sciences (ISSN: 2303-4521)

Mackare, K., Jansone, A. (2019b). Personalized learning: Effective e-material formatting for users without disabilities or specific limitations, Proceedings of ERD2019, The 10th anniversary International Conference of Education, Research and Development (23-27 Aug. 2019, Burgas, Bulgaria)

Nielsen, J. (2000). Designing Web Usability: The Practice of Simplicity, New Riders Publishing, Indianapolis, 2000, p. 420.

Rayner, K. (1998). Eye movements in reading and information processing: 20 years of research, Psychological Bulletin. 1998. Vol.124 p.372-422

Simon K. (2019). Digital 2019: Global Internet Use Accelerates, Report from We Are Social and Hootsuite, available at https://wearesocial.com/blog/2019/01/digital-2019-global-internetuse-accelerates

Yan, Z., Hu, L., Chen, H., Lu, F. (2008). Computer Vision Syndrome: A widely spreading but largely unknown epidemic among computer users. Comput Human Behav. 2008;24: 20262042.

Zacks, J.M., Speer, N.K., Reynolds, J.R. (2009). Segmentation in reading and film comprehension, J. Exp. Psychol Gen. 2009;138: 307-27.

Zigunovs, M., Jansone, A., Mackare, K. (2018). E-learning material adaptive software development, Presentation of ICIC18, The 2nd International Conference of Innovation and Creativity (5-7 Apr. 2018, Liepaja, Latvia)

Ziverte, A. (2018). Methods of adjusting electronic text documents (Original: Elektronisku teksta dokumentu pielāgošanas metodes), Master thesis, Liepaja University, Latvia

Received September 2, 2019, accepted September 7, 2019 